ROCZNIKI TEOLOGICZNE

Tom LXVI, zeszyt 2 - 2019

DOI: http://dx.doi.org/10.18290/rt.2019.66.2-3

KARL-HEINZ MENKE

\title{
JOSEPH RATZINGERS ANTWORT \\ AUF DIE RELIGIONSGESCHICHTLICHE RELATIVIERUNG DES CHRISTENTUMS
}

\author{
JOSEPH RATZINGER'S ANSWER ON THE RELIGIOUS-HISTORICAL \\ RELATIVIZATION OF CHRISTIANITY
}

\begin{abstract}
A b s t r a c t. Joseph Ratzinger, who is author of the teaching document "Dominus Iesus", published by Pope John Paul II at the turn of the millennium, opposes the relativisation of the Christian truth claim as it is made from the perspective of comparative religion. He distinguishes between an ascendant variation of religion (which is also called 'Asian' or 'related to mysticism') and a descendent variation of religion (which is also called 'monotheistic' or 'revelatory'). The former is determined by the relativisation of all dogmatic statements in favour of a transcendent truth, which each may interpret in their own way. The descendant variation, on the other hand, takes God, not man as a starting point. It is - whether in the form of Judaism, Christianity or Islam - monotheistic. For it is based on the personal self-revelation of the one and only Creator in the finitude of space and time. Whereas Judaism identifies the one and only truth of God with the history experienced and remembered by the people of Israel, Islam identifies the only truth of God with a book, the Qu'ran, as it is very much in contrast to Christianity where the person of Jesus Christ is considered the only truth of God. According to Joseph Ratzinger it makes a huge difference whether a person or a book is regarded to be the self-revelation of the absolute, i.e. God. This is because a person is not an object. The only logic that does justice to a person is the dia-logic, i.e. inter-communication or inter-action. A Christianity which remains faithful to its origin and to its true nature can never, as the emeritus Pope emphasizes by distancing himself from the Heidelberg Egyptologist Jan Asmann, commit any kind of violence against dissenters. Because the God whom Chri-
\end{abstract}

KARL-HeINZ MENKE - Ordinarius für Dogmatik (2000-2016) an der Katholisch-Theologischen Fakultät der Universität Bonn; Verfasser zahlreicher Bücher und Abhandlungen, die in verschiedene europäische Sprachen übersetzt wurden; ordentliches Mitglied der NRW-Akademie der Wissenschaften; Mitglied mehrerer Kommissionen der deutschen Bischofskonferenz; Mitglied der Internationalen Theologenkommission; 2017 Träger des Joseph-Ratzinger-Preises. 
stians testify is none other than the man who said of himself, "He who has seen me has seen the Father." (Joh 14.9) He is none other but the Redeemer, who allows Himself to be crucified rather than imposing something through violence, and may it objectively be the best which could be wished for.

Key words: "Dominus Iesus"; ascendant and descendent Religion; Relativization of Christianity; personal truth; unity of truth; Joseph Ratzinger.

Zumindest von deutschen theologischen Fakultäten kann ich sagen: Es gibt kaum ein Thema, das so sehr in den Mittelpunkt gerückt ist wie das Thema der Verhältnisbestimmung des Christentums zu den anderen Religionen, vorab natürlich zum Judentum und zum Islam. Doch statt in diesem Kontext den Wahrheitsanspruch des Christentums zu reflektieren, dominiert die religionsvergleichende Relativierung. Es war Joseph Kardinal Ratzinger, der im Auftrag von Papst Johannes Paul II. zur Jahrtausendwende das Dokument 'Dominus Iesus' über die Einzigkeit und Heilsuniversalität Jesu Christi und der Kirche verfasst hat. Und nicht zufällig trägt die letzte Monographie, die der Kardinalpräfekt der Glaubenskongregation vor seiner Wahl zum Papst veröffentlicht hat, den Titel: „Glaube - Wahrheit - Toleranz. Das Christentum und die Weltreligionen“.

In einer durch das Internet und die Globalisierung vieler Lebensbereiche vernetzten Welt ist auch unter praktizierenden Katholiken die Meinung weit verbreitet, es gebe so viele Religionen, dass die Erklärung des Christentums als der einzig wahren Religion notwendig anachronistisch, vermessen und intolerant erscheine.

Joseph Ratzinger antwortet auf diesen Trend mit einer an Gründlichkeit schwer überbietbaren Reflexion des christlichen Wahrheitsanspruchs. Und nicht nur das; er bietet auch eine Widerlegung der von Religionswissenschaftlern oft geäußerten These, es gebe so viele verschiedene Religionen, dass sich die Frage nach der wahren Religion von selbst erübrige.

\section{ASZENDENTE (BZW. MYSTIZISTISCHE) \\ UND DESZENDENTE (BZW. REVELATORISCHE) RELIGIONEN}

Wenn man einmal vom Pantheismus des mythischen Weltbildes absieht, gibt es - so erklärt Joseph Ratzinger ${ }^{1}$ - letztlich nur zwei Spielarten von

\footnotetext{
1 Vgl. Joseph RAtzinger, Glaube - Wahrheit - Toleranz. Das Christentum und die Weltreligionen, Freiburg ${ }^{4} 2005,14-37$.
} 
Religion: eine aszendente (bzw. ,mystizistische') und eine deszendente (bzw. ,revelatorische') Spielart.

Betrachten wir zunächst die mystizistische Spielart: Mystizismus ist klar zu unterscheiden von Mystik. Der Begriff ,Mystik‘ beschreibt das Bemühen eines Gläubigen, Gott bzw. das Göttliche als Wirklichkeit zu erfahren. Von Karl Rahner stammt der oft zitierte Satz: „Der Fromme von morgen wird ein, Mystiker sein, einer, der etwas, erfahren hat, oder er wird nicht mehr sein“"2, Rahner will damit sagen, dass heute auf Dauer wohl nur Christ bleibt, wer nicht nur einer Tradition oder Gewohnheit folgt, sondern sich selbst von dem überzeugt hat, was er glaubt. Der Begriff ,Mystizismus“ hingegen beschreibt Methoden der Religionsgeschichte, die den Menschen lehren, alle Differenzen zu überwinden. Innerhalb mystizistischer Religionen ist Gott bzw. das Göttliche kein Gegenüber, keine Person, sondern Inbegriff der Aufhebung jeder Differenz. Erst wenn das Ich das Bewusstsein seiner selbst (der Unterscheidung zwischen Ich und Nicht-Ich) überwunden hat, ist es eins geworden mit dem Ewigen und Unendlichen. Die Hochkunjunktur des asiatischen Mystizismus in der westlichen Welt ist maßgeblich motiviert durch die Relativierung aller dogmatischen Aussagen zugunsten einer transzendenten Wahrheit, die wie eine Projektionsfläche aller religiösen Vorstellungen, Symbole und Riten erscheint. Viele Zeitgenossen wählen sich aus unterschiedlichen Traditionen das aus, was dem eigenen Ich Entlastung von Widerständen, von Geboten und Verboten, von Festlegungen und überhaupt von allem Endlichen, Begrenzten, kurzum: ,Differenten', verspricht. Mystizistische Religiosität ist bestimmt von Privatisierung und Innerlichkeit, von der Rückführung alles Bestimmten auf ein Unbestimmbares, zum Beispiel des Personalen auf das Inpersonale. In der auf Plotins Philosophie basierenden Mystik geht es um die Aufhebung aller Unterschiede in die schlechthinnige Einheit des Göttlichen. Ähnlich in fast allen Gestalten der asiatischen Religionen: Der Kreislauf der Wiedergeburten soll sich aufheben in das Ewig-Eine; das Ich in das NichtIch, das Werden in das Sein. Buddhas Weg der Erleuchtung - so erklärt Joseph Ratzinger - ,ist der Weg aus dem Durst nach Sein hinein in das, was uns als Nichtsein erscheint, das Nirwana. Das bedeutet: In der Welt selbst ist keine Wahrheit. Die Wahrheit geschieht im Heraustreten aus ihr. In diesem Sinn ist die Wahrheitsfrage in die Frage der Erlösung aufgelöst, oder auch:

\footnotetext{
${ }^{2}$ Karl RAHNER, Frömmigkeit früher und heute, in: Schriften VII, Einsiedeln 1966, 11-31; 22. - Dazu: Harvey D. EGAN, „Der Fromme von morgen wird ein 'Mystiker' sein”. Mystik und die Theologie Karl Rahners, in: Herbert VORGRIMLER (Hg.), Wagnis Theologie. Erfahrungen mit der Theologie Karl Rahners, Freiburg 1979, 99-112.
} 
in ihr aufgehoben. Die Götter gibt es, aber sie gehören der Welt des Vorläufigen, nicht dem endgültigen Heil $\mathrm{zu}^{\text {“33. }}$

Die britischen und amerikanischen Protagonisten der unter der Bezeichnung ,Pluralistische Religionstheologie“ (PRT) vereinten Bewegung bekunden immer wieder ihre natürliche Affinität zu der von Ratzinger ,mystizistisch genannten Religiosität. Denn auch sie bezeichnen Gott bzw. das Göttliche bzw. die ,absolute" oder ,unbedingte" Wahrheit als das ,Transzendente an sich “4. Sie berufen sich auf Plotins Philosophie des ,schlechthin Einen', auf Immanuel Kants Unterscheidung zwischen der ,Wahrheit an sich ' (voov $\mu \varepsilon v$ -

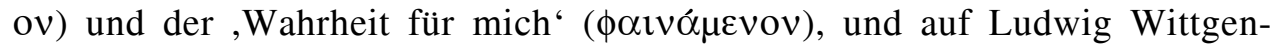
steins Sprachspieltheorie. Unter ,Offenbarung 'verstehen sie nicht das Offenbarwerden Gottes selbst in Welt und Geschichte, sondern alle Versuche der Religionsgeschichte, die an und für sich unzugängliche Wahrheit anthropomorph zu symbolisieren und zu veranschaulichen. So gesehen ist jeder exklusive oder inklusive (andere Wahrheitsansprüche in den eigenen inkludierende) Wahrheitsanspruch einer Religion ein Rückfall in die verhängnisvolle Unterscheidung zwischen wahrer und falscher Religion. Allerdings kennt John Hick, der m. E. bekannteste Vertreter der PRT, einen Wettbewerb der Religionen. Denn - so meint er - diejenige Religion darf als die relativ ,wahrere“ gelten, die mehr Menschen als die konkurrierenden Religionen aus Egoisten (Ich-Zentrierten) zu Altruisten (Du-Zentrierten) formt. Das Kriterium für ein 'Plus' an Wahrheit liegt dann nicht in der Theorie, sondern in der Praxis. Doch - so fragt Ratzinger ${ }^{5}$ - in welcher Praxis? Wer bestimmt, was Altruismus ist? Der Kommunismus oder eine andere politische Utopie, der Konsens einer Elite oder der kleinste gemeinsame Nenner? „Im Denken von John Hick“, so erklärt Ratzinger, „,berührt sich auf eine merkwürdige Weise die postmetaphysische Philosophie Europas mit der negativen Theologie Asiens, für die das Göttliche nie selbst und unverhüllt in die Welt des Scheins treten

${ }^{3}$ J. RATZINGER, Glaube - Wahrheit - Toleranz, 183.

${ }^{4}$ Vgl. J. RATZINGER, Glaube - Wahrheit - Toleranz, 93-111.

5 „Wenn die Forderung nach Orthopraxie einen Sinn haben soll, dann muss es auch eine für jedermann erkennbare gemeinsame Praxis geben, die über das allgemeine Gerede von IchZentrierung und Du-Beziehung hinausgeht. Schließt man den rituellen Sinn aus, der in Asien gemeint war, so kann 'Praxis' ethisch oder politisch verstanden werden. Orthopraxie würde im ersten Fall ein inhaltlich klar definierbares Ethos voraussetzen. Das wird freilich in der relativistischen Ethik-Diskussion durchaus ausgeschlossen: Das an sich Gute und das an sich Schlechte gebe es nun einmal nicht. Versteht man die Orthopraxie aber politisch-gesellschaftlich, dann ist wiederum die Frage, was richtiges politisches Handeln ist". (J. RATZINGER, Glaube - Wahrheit - Toleranz, 101). 
kann, in der wir leben: Es zeigt sich immer nur in relativen Spiegelungen und bleibt selbst jenseits aller Worte und jenseits allen Begreifens in absoluter Transzendenz"6.

Anhänger mystizistischer Religiosität kennen viele Praktiken des Bewusstseinstrainings und der 'transzendentalen Meditation'. Aber sie beten nicht zu einem göttlichen ,Du'. Ob Gott überhaupt personal zu verstehen ist, kann so erklären sie - nicht entschieden werden. Die Vielfalt der Religionen erscheint aus ihrer Sicht der schlagende Beweis für die Unmöglichkeit, göttliche Offenbarung von menschlicher Interpretation zu unterscheiden. Doch eben diese Unterscheidung ist konstitutiv für jeden der drei abrahamitischen Monotheismen.

Nicht von ungefähr spricht die Religionswissenschaft von der "Revolution", die die aszendente Perspektive der mystizistischen Religionen durch die deszendente Perspektive der Offenbarungsreligionen ersetzt. Natürlich kann man die These vertreten, dass auch der Pantheismus ein Monotheismus sei. Doch im eigentlichen Sinne gelten nur die Religionen als Monotheismen, die einen personalen Schöpfer und Offenbarer voraussetzen. Ein personaler Offenbarer ist nicht der Fluchtpunkt anthropogener Projektionen, sondern im Gegenteil der Logos, der allem menschlichen Verstehen bedingend zugrundeliegt. Ein personaler Schöpfer vermag sich durch die Fakten der Schöpfung und der Geschichte seinen Adressaten mitzuteilen. Unter der Voraussetzung eines kontingenten Schöpfungsaktes sind Differenz, Vielheit, Endlichkeit und Zeitlichkeit nicht das zu überwindende ,Nichts' asiatischer Mystik, sondern Ansprache Gottes an den Menschen.

Vielleicht ist die von dem deutschen Ägyptologen Jan Assmann ausgelöste Monotheismus-Debatte ${ }^{7}$ auch nach Polen gelangt - obwohl seine Thesen alles andere als neu sind. Sie trafen den Zeitgeist; sie waren Wasser auf die Mühlen der zeitgenössischen Religionskritik. Was Assmann über den Zusammenhang des abrahamitischen Monotheismus mit der Unterscheidung zwischen wahrer und falscher Religion und der daraus ableitbaren Gewalt gegenüber Andersdenkenden schreibt, ist im Wesentlichen eine Neuauflage der

\footnotetext{
${ }^{6}$ J. RATZINGER, Glaube - Wahrheit - Toleranz, 98.

${ }^{7}$ Vgl. Jan Assmann, Die Mosaische Unterscheidung oder Der Preis des Monotheismus, München 2003; Ders., Exodus. Die Revolution der Alten Welt, München 2015. - Ähnlich wie Assmann urteilt: Regina M. SchwarTz, The Curse of Cain. The Violent Legacy of Monotheism, Chicago 1997. - Zu wichtigen Unterscheidungen zwischen den abrahamitischen Monotheismen: Ekkehard NoRDHOFEn, Corpora. Die anarchische Kraft des Monotheismus, Freiburg 2018.
} 
schon vor zweihundert Jahren von David Hume vorgetragenen Monotheismus$\mathrm{Kritik}^{8}$. In seinem 2017 erschienenen Bestseller „Die Macht des Heiligen“ hat Hans Joas nachgewiesen, wie detailgetreu sich Assmanns Ausführungen mit denen David Humes decken ${ }^{9}$.

Der Exodus Israels aus Ägypten ist aus beider Sicht die Initiation der verhängnisvollen Unterscheidung zwischen wahrer und falscher Religion. In panentheistischen bzw. polytheistischen Religionen gibt es, so meinen Hume und Assmann, die Idee falscher Götter nicht; im Gegenteil, die Götter verschiedener Kulturen sind unter verschiedenen Namen für dieselben Belange oder Bereiche zuständig und daher miteinander kompatibel. Wo aber Kompatibilität und Koexistenz herrschen, können Krieg und Gewalt nicht die Durchsetzung der Wahrheit gegen die Unwahrheitt sein. Assmann weiß, dass die religionsgeschichte Entwicklung vom Polytheismus zum Monotheismus nicht revidierbar ist. Aber er hält die 'Mosaische Unterscheidung' zwischen wahrer und falscher Religion für die Wurzel aller religiös motivierten Gewalt und deshalb die Suspension der Wahrheitsfrage für ein Gebot der Stunde. Deshalb ist er ein Freund der Wittgensteinschen Sprachspieltheorie ${ }^{10}$, des post-

${ }^{8}$ Vgl. David Hume, The Natural History of Religion (1757), in: DeRs., Principal Writings on Religion, Oxford 1993, 134-193 [ins Deutsche übers. u.hg. v. Lothar Kreimendahl: Die Naturgeschichte der Religion, Hamburg 1984].

${ }^{9}$ Humes ,vierte These [...] hat besondere Sprengkraft. Ihr zufolge ist der Polytheismus seinem Wesen nach toleranter als der Monotheismus, da es leicht sei, in ein heterogenes Pantheon auch neue Götter zu integrieren, wärend Monotheismen per defoinitionem darauf drängten, die Verehrung keines anderen Gottes zuzulassen. Angesichts ihrer Tendenz zur Unterdrückung oder Vernichtung konkurrierender Religionen und der in die Monotheismen eingebauten Spaltungs-, Missions- und Expansionstendenzen sei Toleranz nur schwer mit ihren Prämissen vereinbar. [...] In einer Zeit, in der auch die meisten aufgeklärten Kritiker des Christentums nicht an der moralischen Überlegenheit des Christentums gegenüber anderen Religionen zweifelten, erhob Hume den sensationellen Anspruch, unter dem Gesichtspunkt des Friedens nicht nur allen Religionen ein gefährliches Potential, sondern der vernünftigeren Religion sogar ein größeres Gefahren- ja sogar Gewaltpotential zuzuschreiben. [...] Die These vom Gewaltpotential des Monotheismus [...] ist irritierenderweise hierzulande heute als 'Assmann-These' bekannt, obwohl sie sich in sehr ähnlicher Gestalt schon zweieinhalb Jahrhunderte früher bei Hume findet“. (Hans Jonas, Die Macht des Heiligen. Eine Alternative zur Geschichte von der Entzauberung, Berlin 2017, 36f).

${ }^{10}$ Ratzinger bemerkt mit Blick auf Assmanns Wittgenstein-Rezeption: Wittgenstein hat „,in einem seiner vielen Notizbücher notiert, dass es für die christliche Religion nichts ausmachen würde, ob Christus irgendeine der von ihm berichteten Dinge tatsächlich so vollbracht oder sogar überhaupt existiert habe. Dem entspricht die These Bultmanns, an einen Gott, den Schöpfer Himmels und der Erde zu glauben, bedeute nicht, dass man glaube, Gott habe wirklich Himmel und Erde geschaffen, sondern nur, dass man sich selbst als Geschöpf verstehe und dadurch ein sinnvolleres Leben lebe. Ähnliche Vorstellungen haben sich inzwischen in der 
modernen Protestes gegen jedes Einheitsdenken und ein Freund der asiatischen Religionen.

Joseph Ratzinger hält Assmanns Analyse nicht für schlechthin falsch, wohl aber die meisten seiner Schlussfolgerungen ${ }^{11}$. Der Weg der Religionsgeschichte vom Mythos bzw. Polytheismus zum Monotheismus ist - so erklärt er - ähnlich unvermeidlich wie die Religionskritik der griechischen Vorsokratiker. Der Monotheismus ist aus seiner Sicht das notwendige Ergeb-

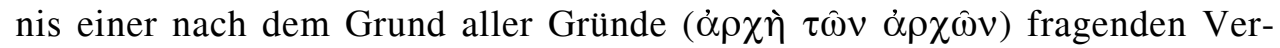
nunft. Auch ein Jan Assmann kann nicht bestreiten, dass die polytheistisch geprägte Welt Ägyptens von Ungerechtigkeit, Gewalt und Krieg bestimmt war. Und das nicht trotz, sondern wegen des Polytheismus. Denn in jeder mythisch bzw. polytheistisch geprägten Welt wird alles Sein und Geschehen auf Götter zurückgeführt. Das Aufkommen von Sturm und Wind, die Bewegung der Wolken, der Sterne, des Meeres - in all dem äußern sich die Kräfte der Götter. Helios bewirkt die Bewegung der Sonne, Athene bewirkt praktische Intelligenz, Apollos musikalische Entrücktheit, Aphrodite die Verliebtheit. Und - das erscheint Ratzinger in seiner Entgegnung auf Assmann wesentlich - auch für böse Gedanken, für Intrigen und Krieg, für Mord und Rache sind bestimmte Götter zuständig. Deshalb sind Krieg und Gewalt, Hass und Rache so selbstverständlich wie Sonne und Mond. Ratzinger verweist in diesem Zusammenhang auf den Kirchenvater Athanasius, der - mit der Religion Ägyptens wohlvertraut - in der Bekehrung der Völker zum Christentum ein Ende religiös motivierter Gewalt, ja, die Erfüllung der jesajanischen Vision von der Umformung der Schwerter zu Pflugscharen (Jes 2,4) sieht ${ }^{12}$.

Mit diesem Hinweis will Ratzinger in keiner Weise bestreiten, dass Menschen, die sich zu Unrecht Christen nannten und sich zu Unrecht auf Christus

katholischen Theologie ausgebreitet und werden mehr oder weniger deutlich auch in der Verkündigung vernehmbar [konsequent durchgeführt von: Gotthold Hasenhüttl, Glaube und Mythos]. Die Gläubigen spüren es und fragen sich, ob man sie eigentlich an der Nase herumgeführt habe. In schönen Fiktionen zu leben, mag den Theoretikern der Religion gegeben sein; für den Menschen, der die Frage stellt, womit und wofür er leben und sterben könne, langen sie nicht. Der Abschied vom Wahrheitsanspruch, der der Abschied vom christlichen Glauben als solchem wäre, wird hier damit verzuckert, dass man Glaube als eine Art von Verliebtheit mit ihren schönen subjektiven Tröstungen oder als eine Art von Spielwelt neben der realen Welt weiter bestehen lässt. Der Glaube wird auf die Ebene des Spiels verlagert, während er bisher die Ebene des Lebens als solchen betraf“. (Glaube - Wahrheit - Toleranz, 174f).

${ }^{11}$ Vgl. J. RATZINGER, Glaube - Wahrheit - Toleranz, 170-186.

${ }^{12}$ Vgl. Athanasius von AleXAndrien, De incarnatione Verbi (Sources Chrétiennes 199), hg. v. Charles Kannengießer, Paris 1973, 51,4 (S. 450). 
beriefen, Gewalt angewandt und gemordet haben. Deswegen beschwört er beispielsweise in seinem Dialog mit Jürgen Habermas ${ }^{13}$ - die bleibende Gefahr einer Religion ohne Glauben, die Gefahr eines Christentums, das seine kulturelle Verwurzelung in Sprache, Nation, Kultur und Politik nicht mehr von Gottes Tora bzw. Logos richten und läutern lässt. In der von Assmann verklärten Welt des ägyptischen Polytheismus gibt es eine solche Läuterung nicht. Denn dort fehlt jede Unterscheidung zwischen göttlichem und innerweltlichem Logos. Alles, was ist und geschieht, ist Epiphanie einer Gottheit. Also ist der einzelne Mensch auch dann, wenn er mordet oder Verrat begeht, nur das Phänomen einer in seinem Denken und Handeln erscheinenden Gottheit. Es gibt in einer polytheistisch bestimmten Welt keine Verantwortung des Menschen gegenüber Gott bzw. den Göttern Es gibt auch keine Menschenrechte und schon gar keine universalisierbaren Gebote und Verbote.

\section{DIE EINZIGKEIT GOTTES, DIE EINZIGKEIT DER WAHRHEIT UND DIE EINZIGKEIT JESU CHRISTI}

Die Bewährung des jüdischen und des christlichen Monotheismus vor der kritischen Vernunft - d.h. konkret: vor dem Forum aller universitären Wissenskontexte - ist keine von außen kommende Forderung, sondern wesentliches Implikat der biblisch bezeugten Heilsgeschichte. Ratzinger erklärt: „Die Bibel ist nicht einfach Ausdruck der Kultur des Volkes Israel, sondern sie liegt ständig im Streit mit dem ganz natürlichen Versuch dieses Volkes, einfach es selbst zu sein, sich in seiner eigenen Kultur einzuhausen. Der Glaube an Gott und das Ja zum Willen Gottes wird ihm ständig gegen seine eigenen Vorstellungen und Wünsche abgerungen. [...] Vom Zorn Gottes und des Mose gegen den Kult des goldenen Jungstiers am Sinai angefangen bis hin zu den späten nachexilischen Propheten geht es immerfort darum, dass Israel aus seiner eigenen kulturellen Identität und seinen religiösen Wünschen herausgerissen wird, dass es sozusagen den Kult der eigenen Nationalität, den Kult von ,Blut und Boden“ lassen muss, um sich dem ganz anderen, dem nicht-eigenen Gott zu beugen, der Himmel und Erde geschaffen hat und der der Gott aller Völker ist. Der Glaube Israels bedeutet eine fortwährende Selb-

\footnotetext{
${ }^{13}$ Vgl. das Gespräch zwischen Jürgen Habermas (Vorpolitische Grundlagen des demokratischen Rechtsstaates?, in: Dialektik der Säkularisierung. Über Vernunft und Religion, hg. v. Florian Schuller, Freiburg 2005, 15-37) und Joseph Ratzinger (Was die Welt zusammenhält. Vorpolitische moralische Grundlagen eines freiheitlichen Staates, in: Ebd. 39-60).
} 
stüberschreitung der eigenen Kultur ins Offene und Weite der gemeinsamen Wahrheit hinein. Die Bücher des Alten Testaments mögen in vieler Hinsicht weniger fromm, weniger poetisch, weniger inspiriert erscheinen als bedeutende Stellen der heiligen Bücher anderer Völker. Aber sie haben doch ihre Einzigartigkeit in diesem Streitcharakter des Glaubens gegen das Eigene, in diesem Aufbruch aus dem Eigenen heraus, der mit Abrahams Wanderschaft beginnt. [...] Und Christus [...] führt diese Grundrichtung des Alten Testaments zu ihrem logischen Ziel: Er bedeutet vollends die Universalisierung dieses Glaubens, der vom Eigenen einer völkischen Ordnung gelöst wird. Nun sind alle Völker eingeladen, in diesen Prozess der Überschreitung des Eigenen einzutreten, der zuerst in Israel begonnen hat; sie sind eingeladen, sich zu dem Gott hinzukehren, der sich in Jesus Christus seinerseits selbst überschritten [...] hat (Eph 2,14). [...] Glaube an Jesus Christus ist also seinem Wesen nach fortwährendes Sichöffnen, Einbruch Gottes in die menschliche Welt und darauf antwortender Aufbruch des Menschen zu Gott hin, der zugleich die Menschen zueinander führt. Alles Eigene gehört nun allen, und alles andere wird zugleich auch unser Eigen" ${ }^{14}$.

Alle drei abrahamitischen Religionen Judentum, Christentum und Islam stimmen darin überein, dass der Einzigkeit Gottes die Einzigkeit der Wahrheit entspricht ${ }^{15}$; dass es nicht mehrere Wahrheiten nebeneinander geben kann; und dass die alle Wirklichkeit begründende Wahrheit offenbar geworden ist in der Endlichkeit von Welt und Geschichte. Und doch besteht zwischen dem jüdischen und dem christlichen Monotheismus einerseits und dem islamischen Monotheismus andererseits eine grundlegende Differenz. Denn es macht einen gewaltigen Unterschied, ob die eine und einzige Wahrheit als Geschichte, als Person oder als Buch erklärt wird. Wiederholt betont Ratzinger, dass man Judentum und Christentum mit der Bezeichnung ,Buchreligion' nicht erfasst; das Judentum deshalb nicht, weil die hebräische Bibel zwar authentische Bezeugung des göttlichen Willens, nicht aber Gottes Wort ist; und das Christentum noch weniger, weil in ihm ausschließlich die Person Jesu Christi mit Gottes Gegenwart in Welt und Geschichte identifiziert wird ${ }^{16}$. Im Judentum

\footnotetext{
14 J. RAtZinger, Glaube - Wahrheit - Toleranz, 160f. - Schon in seinen frühen Studien zu Origenes und Augustinus (in: Gesammelte Schriften I, Freiburg 2011, 571-607) und zum Thema „Christliche Brüderlichkeit“ (in: Gesammelte Schriften VIII/1, Freiburg 2010, 37-118) thematisiert Ratzinger die Unterscheidung zwischen einer Einheit, die ethnisch, kulturell, ökonomisch, politisch oder kultisch begründet ist, von der Einheit aller Menschen, die das Sinnziel der Erwählung Israels und der Auftrag der Kirche ist.

15 Dazu: J. RATZINGER, Glaube - Wahrheit - Toleranz, 14-45.

16 „Der Glaube bezieht sich nicht einfach auf ein Buch, das als solches einzige und letzte
} 
ist die Offenbarkeit Gottes ein durch Erinnerung mündlich und schriftlich tradiertes Geschehen zwischen JHWH und seinem Volk Israel, nicht aber ein $\mathrm{Buch}^{17}$. Und im Christentum ist die Offenbarkeit Gottes identisch mit Jesus Christus und dessen authentischer Bezeugung durch die aus ihm lebende Kirche. Das Neue Testament besteht aus authentischen Bezeugungen des Fleisch gewordenen Wortes Gottes; aber es ist nicht identisch mit dem Wort Gottes.

Die im Kontext des jüdisch-christlichen Dialogs neu bewusst gewordene Kontinuität kann und darf die Diskontinuität nicht ausblenden. Ein Beispiel für solches Ausblenden der Differenz zwischen Christentum und Judentum ist die These, Jesus Christus sei letztlich nichts anderes als die Person gewordene Tora. Einige Protagonisten des christlich-jüdischen Dialogs begründen diese These durch folgende Neu-Übersetzung des Johannes-Prologs: „Im Anfang war die Tora, und die Tora war bei Gott, und die Tora war Gott. Im Anfang war sie bei Gott. Alles ist durch die Tora geworden, und ohne die Tora wurde nichts, was geworden ist. In ihr war das Leben, und das Leben war das Licht der Menschen. [...] Und die Tora ist Fleisch geworden und hat unter uns gewohnt" (Joh 1,1-4.14). - Doch: Diese Übersetzung ignoriert, dass Juden auf keinen Fall sagen: „Und die Tora war Gott“. Außerdem kann man die zitierten Verse nicht vom Rest des Johannes-Prologs trennen. In Joh 1,17 lesen wir: „Denn das Gesetz wurde durch Mose gegeben, die Gnade und die

Instanz für den Glaubenden wäre. In der Mitte des christlichen Glaubens steht nicht ein Buch, sondern eine Person - Jesus Christus, der selbst das lebendige Wort Gottes ist und sich sozusagen in den Wörtern der Schrift auslegt, die aber umgekehrt immer nur im Leben mit ihm, in der lebendigen Beziehung zu ihm recht verstanden werden können. Und da sich Christus die Kirche, das Gottesvolk, als seinen lebendigen Organismus, seinen 'Leib' gebaut hat und baut, gehört zur Beziehung zu ihm das Mitsein mit dem pilgernden Volk, das der eigentlich menschliche Autor und Eigentümer der Bibel ist [...]. Wenn der lebendige Christus die eigentliche Norm der Bibelauslegung ist, so bedeutet dies, dass wir dieses Buch nur recht verstehen im gemeinsamen synchronen und diachronen Glaubensverständnis der ganzen Kirche“. (J. RATZINGER, Unterwegs zu Jesus Christus, Augsburg 2003, 154).

17 Die Bücher der hebräischen Bibel sind nicht so etwas wie vom Himmel gefallene Instruktionen Gottes, sondern aus der Geschichte Israels erwachsene Interpretationen des Lebens Israels mit seinem Bundesgott JHWH. Diese Bücher bleiben toter Buchstabe, wenn sie nicht gelebt werden. Das Volk Israel liegt der hebräischen Bibel ebenso voraus wie die Kirche den Schriften des Neuen Testamentes. Die hebräische Bibel legt sich nicht selber aus. Sie bedarf vielmehr eines Volkes, das sie auslegt. Nicht der einzelne Israelit ist dabei frei von Irrtum, sondern nur Israel in seiner Gesamtheit. Was sich im Leben Israels als Interpretation des göttlichen Willens bewährt und auf Dauer rezipiert wird, findet Eingang in die Sammlung der kanonischen Schriften. - Vgl. J. RATZINGER, Ein Versuch zur Frage des Traditionsbegriffs, in: Gesammelte Schriften IX/1, Freiburg 2016, 391-412. 
Wahrheit kamen durch Jesus Christus“. Offensichtlich unterscheidet der vierte Evangelist sehr klar zwischen dem Wort, das Fleisch geworden ist in Jesus Christus, und dem Gesetz (= Tora). Auch wenn Joh 1,17 keine Abwertung des Gesetzes bedeutet, bleibt der unbestreitbare Sachverhalt, dass Johannes das präexistente, auf die Seite Gottes selbst gerückte und in Jesus Christus Fleisch gewordene Wort nicht als Konkretion, Personifikation oder Wiederholung der Tora Israels, sondern umgekehrt als deren Grund, Ermöglichung, Kriterium und Maßstab betrachtet. Die Tora ist Interpretation des ewigen Logos und nicht umgekehrt der Fleisch gewordene Logos die bloße Veranschaulichung der Tora. Das Befolgen der Tora führt den Israeliten in die Gemeinschaft mit JHWH und ist deshalb Vermittlung desselben Heiles, das auch Jesus verkündet hat. Aber die Tora als solche ist im Unterschied zu Jesus Christus nicht die Gemeinschaft mit JHWH (das ewige Leben). Jesus ist mehr als die Tora ${ }^{18}$, weil er den Willen des Vaters nicht nur interpretiert, sondern „als der am Herzen des Vaters Ruhende“, als der „Einziggezeugte“ des Vaters, als der Einzige, der ihn gesehen hat, von sich sagen darf: „Ich und der Vater sind eins“. (Joh 10,30). Und: „Wer mich gesehen hat, hat den Vater gesehen“. (Joh 14,9b). Und: „Niemand kommt zum Vater außer durch mich“. (Joh 14,6). Papst Benedikt XVI. interpretiert Joh 1,18 im Vergleich mit Ex 33,18-22: Während die Bitte des Mose „Zeige mir, Herr, deine Herrlichkeit!“ (Ex 33,18) die Antwort erhält „Mein Angesicht kannst du nicht schauen. [...] Du kannst meinen Rücken schauen, doch mein Angesicht darfst du nicht sehen“. (Ex 33,20-22), kommt Jesus „aus der unmittelbaren Berührung mit dem Vater, aus dem Dialog von ,Gesicht zu Gesicht “ - aus dem Sehen dessen heraus, der an der Brust des Vaters ruhte“"19. Weil Jesus im Unterschied zu Mose nicht nur Wesentliches über Gott den Vater gesagt hat, sondern das Wort des Vaters selbst war, ist er personal (hypostatisch) derselbe Sohn, der von Ewigkeit her die Selbstaussage des Vaters und also der Logos ist. Oder anders formuliert: Jesus hat in Raum und Zeit (als wahrer Mensch) dieselbe Beziehung zu Gott dem Vater gelebt, die der innertrinitarische Sohn ist ${ }^{20}$.

\footnotetext{
18 Dazu: J. RATZINGER, Israel, die Kirche und die Welt, in: Gesammelte Schriften VIII/2, Freiburg 2010, 1088-1095.

19 J. RATZINGER (BENEDIKT XVI.), Jesus von Nazareth (Gesammelte Schriften VI/1), Freiburg 2013, 144.

${ }^{20} \mathrm{Zu}$ dem Potenzial einer relationalen Ontologie für die Erklärung der Einzigkeit Christi sei hier auf die Arbeiten der Lublinerr Theologen verwiesen: Czeslaw S. Bartnik (exemplarisch: A Personalistic Philosophy of History, in: „Homo Dei“ 11[1984], 193-199) und Krzysztof Góźdź (Jesus Christus als Sinn der Geschichte bei Wolfhart Pannenberg [Est NF XXV], Regensburg 1988, bes. 61-67.73f.).
} 
Trotz der so bezeichneten Differenz zwischen Judentum und Christentum, zwischen jüdischem und christlichem Offenbarungsbegriff, bleibt natürlich wahr, dass die Kontinuität größer ist als die Diskontinuität. Das wird unmittelbar evident, wenn man Judentum und Christentum mit der dritten abrahamitischen Religion vergleicht. Während Judentum und Christentum die Heilige Schrift als zwar authentische, weil inspirierte Zeugnisse von Menschen erklären, identifiziert der Islam den Koran mit dem Wort Gottes. Selbst wenn islamische Theologen zwischen geschriebenem und rezitiertem Wort unterscheiden, sprechen sie von der Präexistenz des Koran. Deshalb ist es nicht verwunderlich, dass Koranschulen keine Orte historisch-kritischer Exegese oder philosophischer Reflexion sind, sondern Schulen der Rezitation und Rezeption.

Wie gesagt: Es macht einen gewaltigen Unterschied, ob eine Person oder ob ein Buch als Selbstoffenbarung des Absoluten bezeichnet wird. Die Wahrheit, die Person ist, wird pervertiert, wenn sie mit heiligen Schriften, mit bestimmten Sätzen, Definitionen oder Interpretationen identifiziert wird. Eine Person wird von vornherein missverstanden, wenn man sie wie einen Gegenstand behandelt. Die einzige Logik, die einer Person gerecht wird, ist die Dia-Logik der Inter-Kommunikation bzw. Inter-Aktion. Deshalb ist alle Rede über die Wahrheit, die Jesus Christus ist - auch wenn es sich bei dieser Rede um inspirierte Schriften oder Dogmen handelt - etwas Nachträgliches gegenüber der Kommunikation mit ihm und mit den Menschen, die ihn als ihren Weg, ihre Wahrheit und ihr Leben bezeugen.

In seiner viel kommentierten Regensburger Universitätsrede ${ }^{21}$ hat Papst Benedikt seinen Hinweis auf die Wahrheit, die Person und nicht Buch ist, mit der Frage verbunden, ob das Wesen des Islam ebenso unvereinbar mit jeder Form von Gewalt ist wie das Wesen des Christentums.

Gewiss, nicht nur der real existierende Islam, sondern auch das real existierende Christentum hat das eigene Wesen allzu oft und viel zu lange durch Anwendung von Zwang und Gewalt verraten. Aber das Christentum war vor der sogenannten ,Konstantinischen Wende' die neue religiöse Bewegung, die sich gegen die Vergötzung politischer und militärischer Gewalt wandte, die die Würde auch des Armen und Benachteiligten, des Macht- und Besitzlosen verteidigte, die Jesu Bergpredigt in die Praxis des privaten und gemeindlichen Lebens zu übersetzen versuchte ${ }^{22}$. Jesus hat im Unterschied zu Muhammad

\footnotetext{
${ }^{21}$ Die „Regensburger Vorlesung “ Papst Benedikts XVI. im Dialog der Wissenschaften, hg. v. Christoph Dohmen, Regensburg 2007.

22 Vgl. Arnold Angenendt, Toleranz und Gewalt. Das Christentum zwischen Bibel und Schwert, Münster 2007, 391-394.
} 
keine Kriege geführt. Und die Väter der ersten christlichen Jahrhunderte kannten noch keine Gewalt gegen die Andersdenkenden in den eigenen Reihen. Das änderte sich erst im Gefolge der für das christliche Mittelalter charakteristischen Vermischung von politischer und kirchlicher Macht. Der christliche Apologet Laktanz ( $†$ 320), von Kaiser Konstantin zum Lehrer seines Sohnes Crispus ernannt, erklärt in seinen „Göttlichen Unterweisungen“ die Kriterien zur Unterscheidung von wahrer und falscher Religion und die Ursprünge des Irrtums, gelangt aber gerade so zu seiner oft zitierten Maxime: „Die Religion ist mehr als alles Sache der Freiwilligkeit, und man kann von niemandem erzwingen, dass er etwas verehre, was er nicht will“"23. Oder der hl. Martin von Tours: Er ist nicht nur durch seine Liebe zu den Armen, sondern auch durch den Protest bekannt geworden, den er im Namen Jesu gegen die politisch motivierte Hinrichtung des Häretikers Priszillian gerichtet hat. Auch der nicht selten als intolerant gebrandmarkte Augustinus ( $\dagger$ 430) verbindet seine Exegese des Unkrautgleichnisses (Mt 13) mit dem Aufruf zur Toleranz gegenüber denen, die sich nicht bekehren lassen. Und in der frühen Neuzeit waren es die spanischen Spätscholastiker Francisco de Vitoria, Domingo de Soto und Melchior Cano, die Jahrhunderte vor der Französischen Aufklärung die unbedingte Würde des je einzelnen Menschen verteidigen zum Beispiel mit der politikkritischen These: „Die Urweinwohner Amerikas sind keine inferioren Halbmenschen. Sie haben die gleiche unverlierbare Menschenwürde wie die Europäer, denn alle Menschen sind vor Gott gleich. Das Naturrecht gilt für alle. Deshalb darf zum Beispiel das Eigentum und das Land der Indios in Süd- und Mittelamerika nicht von den Christen beschlagnahmt und in Besitz genommen werden. Und politische Einmischungen in Länder der Indios oder der Indianer werden erst dann rechtskräftig, wenn diese damit einverstanden sind“24.

Wenn das Christentum seinem Wesen treu bleiben will, darf es die Allmacht des einen und einzigen Gottes nicht anders ${ }^{25}$ denken als die Liebe

23 LuCIUS CAECILIANUS FIRMIANUS LACTANTIUS, Epitome divinarum institutionum (BSGRT Teubner), hg. v. Eberhard Heck u. Atonie Wlosok, Stuttgart 1994, 49.

24 Zitiert nach: Gerhard LOHFINK, Im Ringen um die Vernunft. Reden über Israel, die Kirche und die Europäische Aufklärung, Freiburg 2016, 39.

${ }^{25}$ In seiner berühmt gewordenen 'Einführung in das Christentum' bekennt Joseph Ratzinger: „Jesus hat Gott wirklich aus-gelegt, ihn herausgeführt aus sich selbst, oder, wie es der erste Johannesbrief noch drastischer sagt: ihn unserem Anschauen und unserem Betasten freigegeben, so dass der, den nie jemand gesehen hat, nun unserem geschichtlichen Berühren offensteht“. (Gesammelte Schriften IV, Freiburg 2014, 67f). Diesem Bekenntnis des Jahres 1968 entspricht der programmatische Satz aus dem Vorwort des 2007 erschienenen Jesus-Buches von 
des Gekreuzigten. „Das Kreuz“, so erklärt Papst Benedikt, „,ist die wahre, Höhe. Es ist die Höhe der Liebe, bis zum Ende (Joh 13,1); am Kreuz ist Jesus auf der, Höhe Gottes, der die Liebe ist. Dort kann man ihn 'erkennen', kann erkennen, dass 'ich es bin'. Der brennende Dornbusch ist das Kreuz. Der höchste Offenbarungsanspruch, das 'Ich bin es' und das Kreuz Jesu sind untrennbar“"26. Denn Gott der Vater hat keine anderen Möglichkeiten als der personal bzw. hypostatisch mit dem innertrinitarischen Sohn identische Mensch Jesus ${ }^{27}$. Folglich darf man von der Allmacht Gottes nicht anders denken und reden als von der Ohnmacht des Gekreuzigten. Das mag für alle paradox klingen, die einen vorgefassten Begriff von Allmacht auf Gott projizieren. Aber am Kreuz hat der Vater selbst expliziert, was seine Allmacht ist: Sie ist identisch mit der Liebe des Sohnes, der sich lieber geißeln, mit Dornen krönen und kreuzigen lässt als irgend etwas zu erzwingen. Von eben dieser gekreuzigten Liebe, der man auf Golgotha zuruft: „Hilf dir doch selbst und steig herab vom Kreuz!“ (Mk 15,30); von eben dieser Liebe bekennt der Osterglaube, dass sie stärker war als der kreuzigende Hass ihrer Henker; und dass sie allem gegenteiligen Anschein zum Trotz kein Unglück und keine Sünde verhindern, wohl aber jeden Abgrund unterfassen kann.

Wo immer Gott neuplatonisch als ,schlechthinnige Einheit' oder hegelianisch als ,notwendiger Prozess ' verstanden wird, ist er ein unbezügliches ,Absolutum'; kann er nichts anfangen und nichts lassen, weil er immer schon

Papst Benedikt XVI.: „Et incarnatus est - mit diesem Wort bekennen wir uns zu dem tatsächlichen Hereintreten Gottes in die reale Geschichte“ (Gesammelte Schriften VI/1, Freiburg 2013, 132) - Dazu: Krzysztof GóźDź, Logos-Christologie nach Joseph Ratzinger, in: Logos et Musica. In honorem Summi Romani Pontificis Benedicti XVI, hg. v. Elzbieta Szczurko (Editor), Tadeusz Guz (Editor) u. Horst Seidl, Frankfurt 2012, 153-162.

${ }^{26}$ JOSEPH RATZINGER (BENEDIKT XVI.), Jesus von Nazareth (Gesammelte Schriften VI/1), Freiburg 2013, 408f.

27 „An dieser Frage hängt die Entscheidung, was das Christentum überhaupt ist - ob Jesus zu den 'Avataras', zu den vielgestaltigen Erscheinungsformen der Gottheit in der Welt zählt, ob Christentum eine Religionsvariante unter anderen ist oder ob hier ein anderer Realismus vorliegt. Das Homoousios antwortet auf diese Frage. Es sagt: Das Wort 'Sohn' ist nicht poetisch-allegorisch (mythologisch, symbolisch), sondern ganz realistisch zu verstehen. Jesus ist es wirklich und wird nicht bloß so genannt. Der Realismus des biblischen Glaubens wird verteidigt, nichts sonst; der Ernst des Ereignisses, des neuen und von außen kommenden Geschehens. In diesem 'Ist' klingt das 'Ich bin' der Dornbuschformel nach (Ex 3,14), was immer ihr historischer Ursprungssinn gewesen sein mag. 'Ich bin es' hat Jesus mehr als einmal gesagt und den ganzen Realismus des biblischen Glaubens darin ausgedrückt: Die scheinbar so vorgeschobene Formel des Credo, das Homoousios, sagt uns letztlich nur, dass wir die Bibel beim Wort nehmen dürfen, dass sie in ihren letzten Aussagen wörtlich gilt und nicht bloß allegorisch“. (J. RATZINGER, Glaube - Wahrheit - Toleranz, 77f). 
alles hat und ist. Aussagen über die Kontingenz des Schöpfungsaktes, über die Erwählung Israels und die Stiftung eines Bundes sind widerspruchsfrei nur durch die Trinitätslehre des christlichen Monotheismus erklärbar. Wer die Trinitätslehre als Hindernis des jüdisch-christlichen Dialogs bezeichnet, hat nicht verstanden, dass das christliche Zentraldogma den Monotheismus Isaraels nicht in Frage stellt, sondern verteidigt. Denn der Gott, den die hebräische Bibel als den in der Geschichte redenden und handelnden beschreibt, ist keine unbezügliche Absolutheit, Notwendigkeit und Ewigkeit, sondern Beziehung. Er ist als er selbst das, was er in der biblisch bezeugten Geschichte offenbart. Er ist interpersonale Beziehung, und zwar in der denkbar vollkommensten Weise: nämlich trinitarische Beziehung. Er ist ,Ich“ und ,Du“ zugleich; er ist, wie die Tradition bekennt, wechselseitige Anerkennung von ,Vater' und ,Sohn'. Und weil die interpersonale Beziehung von ,Vater' und ,Sohn' keine bloße Eigenschaft von ,Vater' und ,Sohn', sondern genauso vollkommen wie Vater und Sohn ist, ist auch die wechselseitige Anerkennung der Person des Vaters und der Person des Sohnes gleichwesentlich göttliche Person: nämlich der ,Heilige Geist ${ }^{28}$.

Das christliche Trinitätsdogma ist Ausweis eines Monotheismus, der auf der göttlichen Ebene keine andere Logik als auf der geschöpflichen Ebene duldet. Während der Islam den Menschen auf die für ihn undurchschaubare Logik Allahs verweist, versucht die christliche Trinitätslehre der kritisch fragenden Vernunft zu erklären, warum der biblisch bezeugte und in Christus als der Mensch Jesus offenbare Gott nicht anders allmächtig ist als die nichts erzwingende Liebe des Gekreuzigten.

Eine Theologie, die von Gott nichts anderes sagt als von Christus, erklärt den Logos alles Seienden als Liebe. Liebe aber kann es nur geben als Gewährung wirklicher Freiheit. Liebe setzt sich nicht mit politischen, rhetorischen oder ökonomischen Mitteln durch. Liebe will Gegen-Liebe; und die gibt es nur um den Preis der freien Einsicht und der freien Anerkennung. Also muss das Christentum um der Freiheit seiner Adressaten willen die Religionsund Meinungsfreiheit nicht nur für sich selbst, sondern auch für seine Konkurrenten verteidigen und das eigene Bekenntnis jeder wissenschaftlichen Kritik aussetzen - in der gelassenen Gewissheit, dass die Wahrheit, die Jesus Christus ist, keine Frage irgendeines Wissenschaftlers fürchten muss.

\footnotetext{
${ }^{28}$ Vgl. J. RATZINGER, Der Heilige Geist als communio. Zum Verhältnis von Pneumatologie und Spiritualität bei Augustinus, in: Erfahrung und Theologie des Heiligen Geistes, hg. v. Claus Heitmann u. Heribert Mühlen, München 1974, 223-238.
} 


\section{BIBLIOGRAPHIE}

Angenendt A., Toleranz und Gewalt. Das Christentum zwischen Bibel und Schwert, Verlag Aschendorff, Münster 2007.

Assmann J., Die Mosaische Unterscheidung oder Der Preis des Monotheismus, Verlag Carl Hanser, München 2003.

Assmann J., Exodus. Die Revolution der Alten Welt, Verlag Carl Hanser, München 2015.

Athanasius VON AlEXANDrien, De incarnatione Verbi (Sources Chrétiennes 199), red. Charles Kannengießer, Éditions du Cerf, Paris 1973.

Bartnik Cz.S., A Personalistic Philosophy of History, „Homo Dei“ 11(1984), s. 193-199.

Die „Regensburger Vorlesung“ Papst Benedikts XVI. im Dialog der Wissenschaften, red. Christoph Dohmen, Verlag Friedrich Pustet, Regensburg 2007.

EGAN H.D., „Der Fromme von morgen wird ein ,Mystiker“ sein“. Mystik und die Theologie Karl Rahners, w: H. VorgrimLER (red.), Wagnis Theologie. Erfahrunggen mit der Theologie Karl Rahners, Verlag Herder, Freiburg 1979, 99-112.

GóźDŹ K., Jesus Christus als Sinn der Geschichte bei Wolfhart Pannenberg (Est NF XXV), Verlag Friedrich Pustet, Regensburg 1988.

GóźDź K., Logos-Christologie nach Joseph Ratzinger, w: E. SzCzurko, T. Guz, H. SEIDL (red.), Logos et Musica. In honorem Summi Romani Pontificis Benedicti XVI, Verlag Peter Lang, Frankfurt 2012, 153-162.

HABERMAS J., Vorpolitische Grundlagen des demokratischen Rechtsstaates?, w: F. SCHULLER (red.), Dialektik der Säkularisierung. Über Vernunft und Religion, Verlag Herder, Freiburg 2005, 15-37.

Hume D., The Natural History of Religion (1757), w: TENŻE, Principal Writings on Religion, Verlag Paul Russell, Oxford 1993, 134-193 [przekł. niemiecki L. Kreimendahl, Die Naturgeschichte der Religion, Verlag Felix Meiner, Hamburg 1984].

JonAs H., Die Macht des Heiligen. Eine Alternative zur Geschichte von der Entzauberung, Verlag Suhrkamp, Berlin 2017.

LOHFINK G., Im Ringen um die Vernunft. Reden über Israel, die Kirche und die Europäische Aufklärung, Verlag Herder, Freiburg 2016.

Lucius CAecilianus Firmianus Lactantius, Epitome divinarum institutionum (BSGRT Teubner), red. Eberhard Heck, Atonie Wlosok, Verlag K.G. Saur, Stuttgart 1994.

NoRdhofen E., Corpora. Die anarchische Kraft des Monotheismus, Verlag Herder, Freiburg 2018.

RAHNER K., Frömmigkeit früher und heute, w: Schriften zur Theologie, t. VII, Verlag Benziger, Einsiedeln 1966, 11-31.

RATZINGER J., Der Heilige Geist als communio. Zum Verhältnis von Pneumatologie und Spiritualität bei Augustinus, w: C. HeItMAnN, H. MÜHLEN (red.), Erfahrung und Theologie des Heiligen Geistes, Verlag Kösel, München 1974, 223-238.

RAtZinger J., Unterwegs zu Jesus Christus, Verlag Sankt Ulrich, Augsburg 2003.

RATZINGER J., Glaube - Wahrheit - Toleranz. Das Christentum und die Weltreligionen, Verlag Herder, Freiburg ${ }^{4} 2005$.

RATZINGER J., Was die Welt zusammenhält. Vorpolitische moralische Grundlagen eines freiheitlichen Staates, w: F. SCHULLER (red.), Dialektik der Säkularisierung. Über Vernunft und Religion, Verlag Herder, Freiburg 2005, 39-60.

RATZINGER J., Opera Omnia, t. VIII/1: Kościół - znak wśród narodów, przekł. W. Szymona OP, red. K. Góźdź, M. Górecka, Wydawnictwo KUL, Lublin 2013.

RATZINGER J., Opera Omnia, t. VIII/2: Kościół - znak wśród narodów, przekł. W. Szymona OP, red. K. Góźdź, M. Górecka, Wydawnictwo KUL, Lublin 2013. 
RAtZinger J., Opera Omnia, t. I: Lud i dom Boży w nauce św. Augustyna o Kościele, przekł. W. Szymona OP, red. K. Góźdź, M. Górecka, Wydawnictwo KUL, Lublin 2014.

RAtzinger J., Opera Omnia, t. VI/1: Jezus z Nazaretu. Studia o chrystologii, przekł. M. Górecka. W. Szymona OP, red. K. Góźdź, M. Górecka, Wydawnictwo KUL, Lublin 2015.

RATZINGER J., Opera Omnia, t. IV: Wprowadzenie do chrześcijaństwa. Wyznanie - chrzest nawrócenie, przekł. R. Biel, M. Górecka, red. K. Góźdź, M. Górecka, Wydawnictwo KUL, Lublin 2017.

RATZINGER J., Opera Omnia, t. IX/1: Wiara w Piśmie i w Tradycji. Teologiczna nauka o zasadach, przekł. J. Merecki SDS, red. K. Góźdź, M. Górecka, Wydawncitwo KUL, Lublin 2018.

SChwartz R.M., The Curse of Cain. The Violent Legcy of Monotheism, University of Chicago Press, Chicago 1997.

\title{
JOSEPH RATZINGERS ANTWORT AUF DIE RELIGIONSGESCHICHTLICHE RELATIVIERUNG DES CHRISTENTUMS
}

\author{
$\mathrm{Zu} \mathrm{s}$ a m m e n f a s s u ng
}

Joseph Ratzinger - Verfasser des von Papst Johannes Paul II. zur Jahrtausendwende publizierten Lehrschreibens ,Dominus Iesus' - wendet sich gegen die religionsvergleichende Relativierung des christlichen Wahrheitsanspruchs. Er unterscheidet zwischen einer aszendenten (auch , asiatisch' oder ,mystizistisch' genannten) und einer deszendenten (auch ,monotheistisch' oder , revelatorisch' genannten) Spielart der Religionen. Erstere ist bestimmt durch die Relativierung aller dogmatischen Aussagen zugunsten einer transzendenten Wahrheit, die jeder auf je eigene Weise interpretieren darf. Die deszendente Spielart hingegen geht von Gott, nicht vom Menschen aus. Sie ist - ob in Gestalt des Judentums, des Christentums oder des Islam - wesentlich monotheistisch. Denn sie beruht auf der personalen Selbstoffenbarung des einen und einzigen Schöpfers in der Endlichkeit von Raum und Zeit. Das Judentum identifiziert die eine und einzige Wahrheit Gottes mit der von Israel erfahrenen und erinnerten Geschichte; der Islam mit dem Buch ,Koran'; das Christentum mit der Person Jesu Christi. Es macht - so erklärt Joseph Ratzinger - einen gewaltigen Unterschied, ob eine Person oder ein Buch als Selbstoffenbarung des Absoluten bezeichnet wird. Denn eine Person ist kein Gegenstand. Die einzige Logik, die einer Person gerecht wird, ist die Dia-Logik bzw. Inter-Kommunikation bzw. Inter-Aktion. Ein Christentum, das seinem Ursprung und Wesen treu bleibt, kann, so betont der emeritierte Papst in Absetzung von dem Heidelberger Ägyptologen Jan Asmann, gar keine Gewalt gegenüber Andersdenkenden ausüben. Denn der Gott, den Christen verkünden, ist kein anderer als der Mensch, der von sich gesagt hat: „Wer mich sieht, sieht den Vater“; ist kein anderer als der Erlöser, der sich lieber kreuzigen lässt als irgendetwas, und mag es das objektiv Beste sein, mit Gewalt zu erzwingen.

Schlüsselwörter: „Dominus Iesus“; die aszendenten und deszendenten Religionen; die Relativierung des Christentums; die personale Wahrheit; die Einheit der Wahrheit; Joseph Ratzinger. 


\title{
ODPOWIEDŹ JOSEPHA RATZINGERA NA RELIGIJNO-HISTORYCZNA RELATYWIZACJE CHRZEŚCIJAŃSTWA
}

\author{
St r e s z c z e n i e
}

Joseph Ratzinger - autor dokumentu „Dominus Iesus”, opublikowanego przez papieża Jana Pawła II na przełomie tysiącleci, sprzeciwia się relatywizacji twierdzeń prawdy chrześcijańskiej, ponieważ jest ona tworzona z perspektywy religii porównawczej. Rozróżnia on między religią ascendentną, wytworzoną (zwaną także ,azjatycką” lub „związaną z mistycyzmem”) a descendentną, objawioną religią (zwaną również „monoteistyczną”). Pierwszy model jest zdeterminowany relatywizacją wszelkich wypowiedzi dogmatycznych na rzecz prawdy transcendentnej, którą każdy może interpretować na swój sposób. Natomiast drugi model wychodzi od Boga, a nie od człowieka. Jest on - czy to w formie judaizmu, chrześcijaństwa czy islamu monoteistyczny. Opiera się bowiem na personalnym objawieniu się jedynego Stwórcy w skończoności przestrzeni i czasu. Judaizm utożsamia jedyną prawdę o Bogu z historią doświadczoną i zapamiętaną przez lud Izraela; islam utożsamia jedyną prawdę o Bogu z księgą Koranu, zaś chrześcijaństwo z osobą Jezusa Chrystusa. Według Josepha Ratzingera to ogromna różnica, czy daną osobę czy księgę uważa się za samoobjawienie się Absolutu, tj. Boga. Dzieje się tak, ponieważ osoba nie jest obiektem. Jedyną logiką, która może sprostać osobie, jest dia-logika, tj. komunikacja wewnętrzna czy też interakcja. Chrześcijaństwo, które pozostaje wierne swojemu pochodzeniu i swojej prawdziwej naturze, nigdy nie może - jak podkreśla emerytowany Papież - dystansując się od egiptologa z Heidelbergu, Jana Asmanna, używać jakiejkolwiek przemocy wobec dysydentów. Albowiem Bóg, o którym świadczą chrześcijanie, nie jest nikim innym niż człowiekiem, który o sobie powiedział: „Ten, który mnie widział, widział Ojca” (J 14,9). Nie jest On nikim innym jak Odkupicielem, który pozwala się ukrzyżować, zamiast narzucać coś przez przemoc, i obiektywnie jest najlepszy, jakiego można sobie życzyć.

Słowa kluczowe: „Dominus Iesus”; religia; relatywizacja chrześcijaństwa; prawda osobista; jedność prawdy; Joseph Ratzinger. 